\title{
Modelling in situ mussel ruthenium-106 concentration dynamics due to fluctuating seawater radionuclide concentrations
}

\author{
J. Le Fur ${ }^{1,}{ }^{*}$ P. Germain ${ }^{2}$, Y. Baron ${ }^{3}$ \\ ${ }^{1}$ CEA-SMT/IFREMER CT, BP 330, F-83507 La Seyne/mer Cedex, France \\ ${ }^{2}$ CEA-LRM, BP 508, F-50105 Cherbourg Cedex, France \\ ${ }^{3}$ GA/EAMEA, BP 19, F-50115 Cherbourg Naval, France
}

\begin{abstract}
A 'laboratory' model of radionuclide transfer between marine organisms and seawater was extended with a view to using it in situ. The model was applied to results of experiments performed in situ on the French shores of the English Channel. Therefore 2 first experiments on the transfer of 106ruthenium between Mytilus edulis and its environment were carried out to establish parameters. The results of these experiments confirmed that the model could predict the time-course of concentrations in the organisms, in the accumulation experiment as well as during the elimination phase in which comparison of the results with other work allowed some of the proposed hypotheses to be validated. Once the transfer model had been characterized, it was applied to results obtained in an independent test experiment. The accuracy of the model fitting to the data was not entirely satisfactory but the discrepancy between the estimates and observations was much smaller than that obtained using the standard 'concentration factor' method. The results obtained in the 2 experiments were compared and factors were considered that might be responsible for the differences observed between real and calculated concentrations. Previous work led to the conclusion that the main factor still to be represented in the model was seasonal change in the metabolism of the mussels and more precisely the mussels' weight fluctuations. Although the formulation of the model has yet to be perfected, results obtained indicate that it could constitute a satisfactory tool for describing concentrations of radioactivity in an organism in situ.
\end{abstract}

\section{INTRODUCTION}

One step in determining the fate of radionuclides released into the marine environment is to evaluate the transfer of radionuclides between the seawater and the organisms that live in it. For this purpose, one may use 2 different approaches. The first, most common (Polikarpov 1966, Weaver 1967, Chapman et al. 1968, Ancellin et al. 1979, Amiard-Triquet \& Amiard 1980 IAEA 1985), involves static studies and the use of the 'concentration factor' $(C F)$. CF is a multiplying coefficient which is applied to the radioactive level of the organism's environment to evaluate the concentration of radionuclides in the organism, this coefficient being specific to the organism and to the radionuclide. The

\footnotetext{
- Present address: ORSTOM, CRODT-ISRA, B.P. 2241, Dakar, Senegal
}

use of $C F$ assumes steady-state conditions between the organism and its environment.

In the alternative approach (kinetic studies) the mechanisms governing transfers, in other words the accumulation and elimination of a radionuclide by the organism, are established as accurately as possible. The parameters that quantify these processes are again specific to the organism but the calculation also takes the 'radioactive history' of the organism into account.

Kinetic studies overcome the main drawback of the $C F$ method as they do not have to assume steady-state conditions between the organism and its environment. In the natural environment equilibrium conditions cannot be assumed. Indeed, fluctuations in the source term, mainly due to fluctuations in time and rate of industrial discharges and variations in transport vectors from the discharge source to the organism, constantly modulate the organism's 'response'. Moreover, kinetic studies may give quantitative, or at least qualitative, 
information on transfer kinetics (accumulation and elimination) of the radionuclides between the organisms and their environment. Eventually, if quantitative information is satisfactory, they may allow forecasting of radioactivity levels in organisms submitted to a radioactive source.

Kinetic studies in general involve the use of mathematical models, more often than not based on a compartmental representation of the organism and its environment (e.g. Bernhard et al. 1971, Jefferies \& Hewett 1971, Pentreath \& Jefferies 1971, Aoyama \& Inoue 1973, Pentreath 1973, Thomann 1981, Halford et al. 1983, Badie et al. 1985). These models were first developed for application to laboratory radioactive transfer experiments. In these experiments, the source term is maintained constant or varied in a decreasing exponential form during the sampling interval; the model formulation can then be simplified.

This study has 3 aims: (1) to propose a technique derived from existing models that can be used to represent phenomena occurring in the natural environment, i.e. where the radioactive source term cannot be assumed to be constant; (2) to establish whether the model described is consistent with biological phenomena observed in the complex natural environment (the qualitative aspect); (3) if so to establish the uses and limitations of the model. In this way the parameters that must be taken into account in order to apply the model to forecasting purposes will be searched for (the quantitative aspect).

The example selected for simulations is the in situ study of accumulation and elimination by mussels Mytilus edulis of ruthenium $\left({ }^{106} \mathrm{Ru}\right)$ present in seawater on the French coast of the English Channel (north Cotentin)

The mussel is a lamellibranch mollusc common on the French shores of the Channel. It is extensively bred in the northeast Cotentin region (IFREMER 1984). This organism is also recognized for its qualities as a biological indicator of radioactive pollution (Goldberg et al. 1978, Dahlgaard 1981) and is one of the species collected in the Channel for radiological surveillance purposes (Calmet 1986).

In north Cotentin, most of the radioactivity present in seawater originates from the low-level activity liquid effluents discharged from the irradiated fuel reprocessing plant at La Hague (Guegueniat et al. 1988). The ${ }^{106} \mathrm{Ru}$ discharged in these effluents is known to have a complex physico-chemical behaviour (Guegueniat 1975). Nevertheless, it was selected because it is responsible for the major part of the anthropogenic gamma radioactivity found in mussels in the Channel (Calmet 1986). Using this tracer may in consequence lead to measuring errors, which however should be small.

\section{MATERIAL AND METHODS}

The sampling protocol involved 3 experiments. The first two were designed to provide estimates of the model parameters; one was concerned with the determination of accumulation parameters, the second with those of depuration. The third experiment constituted a test case applying the estimates obtained.

For the first experiment, $300 \mathrm{~kg}$ of adult sub-tidal mussels Mytilus edulis were collected on 15 October 1985 at Barfleur in northeast Cotentin (Fig. 1) and transplanted to Cherbourg, a station influenced by low level activity liquid waste from the La Hague plant. The organisms were bred in continuously submerged $300 \mathrm{~cm}$ diameter mussel baskets. For a period of $8 \mathrm{mo}$ concentrations of ${ }^{106} \mathrm{Ru}$ were monitored in water, sus-

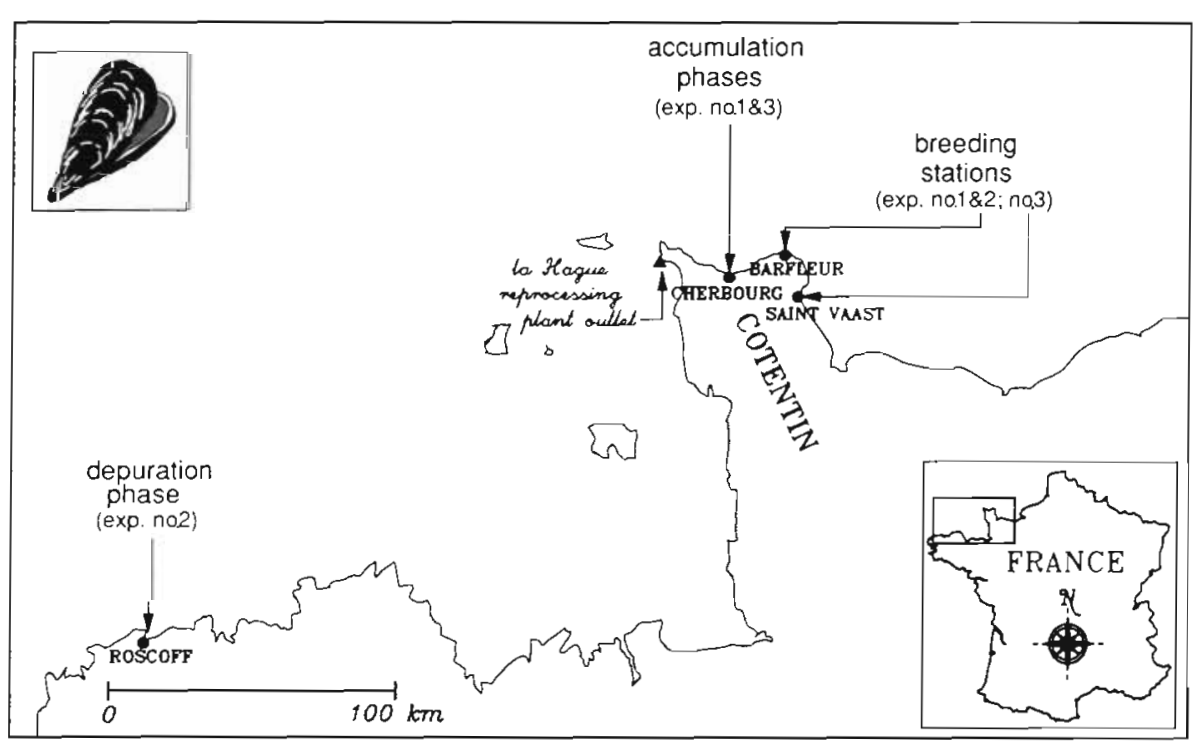

Fig. 1. Mytilus edulis breeding stations and sampling sites 
pended matter, and in the organisms. By the end of this first phase, 21 batches of fresh mussels had been sampled (sampling procedure explained below).

After the $8 \mathrm{mo}$, the mussels were transplanted to Roscoff on the northern coast of Brittany (Fig. 1), away from any industrial radioactive influence (Germain et al. 1988). This constituted the second experiment during which mussels depurated their accumulated radionuclide. Study of this elimination phase was carried out over as long a period as possible in order to show up the long-term capacity of mussels to retain radionuclides. The experiment was thus carried out over a period of $342 \mathrm{~d}$ (4 June 1986 to 12 May 1987) leading to 17 measures of radionuclide concentration in the organisms.

As the second experiment had to be as long as possible, the third experiment was carried out before the first two. The same protocol as described for the first experiment was used. The main differences were the time of year during which this third experiment was carried out $\left(\mathrm{t}_{0}=18\right.$ March 1985) and the breeding station of the mussels used which, for practical reasons, came from Saint-Vaast la Hougue (see Fig. 1). The depuration phase was not carried out since the biological parameters were already established. The experiment lasted $300 \mathrm{~d}$. By the end of the experiment, 22 measurements of ruthenium concentration in the organisms and 40 samples of the organisms' surrounding water had been obtained.

Approximately 300 individuals were sampled at each sampling operation. Except for the second experiment at Roscoff, particle clearance (faeces and pseudofaeces) was allowed for after each sampling operation: each batch of mussels was left for $24 \mathrm{~h}$ in an aquarium with filtered site seawater, 3 times renewed.

The flesh, byssus, shell and particles (faeces and pseudo-faeces) were then separated and dried at $90^{\circ} \mathrm{C}$ to constant weight before being pulverized. Each dried sample was then placed in calibrated dishes for a measurement of 1000 min by Ge-Li gamma spectrometry (Germain et al. 1979). Concentrations of ruthenium-106, $\beta$ emitter, in the organisms were established by measuring its radionuclide daughter, rhodium-106 ( ${ }^{106} \mathrm{Rh}$, $\gamma$ emitter); the ${ }^{106} \mathrm{Ru}$ concentrations reported in fact express concentrations of ${ }^{106} \mathrm{Ru}+{ }^{106} \mathrm{Rh}$.

To determine the seawater ${ }^{106} \mathrm{Ru}$ content, the organisms' surrounding seawater was sampled $5 \mathrm{~d}$ per week $\left(30 \mathrm{l} \mathrm{d}^{-1}\right)$. Each week the whole $150 \mathrm{l}$ were filtered through a $0.45 \mu \mathrm{m}$ filter; the ${ }^{105} \mathrm{Ru}$ was then co-precipitated by $\mathrm{MnO}_{2}$ and counted by means of gamma spectrometry. Values were corrected for the yield of the extraction technique. Recent experiments show that this yield depends on 2 factors. On the one hand it varies with the chemical state of the ruthenium in the effluent which is conditioned by the waste reprocessing treatments in the plant; on the other hand the ruthenium physico-chemical state (and consequently the extraction yield) changes according to the residence time in seawater before sampling. In the present study, a $33 \%$ yield was assumed for the seawater sampling method, reflecting the situation at the time of the experiments (Gandon pers. comm.).

\section{MATHEMATICAL TREATMENT}

The kinetics of the accumulation and elimination phases are represented using a box model. This type of model takes into account radionuclides fluxes between the organism and its environment. Such models are based on the assumption that the transfer rate from compartment $i$ to compartment $j$ is proportional to the quantity of radionuclide in compartment $i$. A differential equation system can then be set up taking into account transfers between the seawater compartment and the organism and between each of the organism's compartments.

In the laboratory model that will be derived, the concentration of radionuclides in seawater is assumed to be constant throughout the experiment and the concentration in the organism at the start of the experiment is assumed to be zero. The analytical solutions were derived from previous studies (Badie et al. 1985, Le Fur 1990). Assuming constant transfer rates, and if $n$ compartments are used to represent the organism, they are of the form:

For the accumulation phase, where both accumulation and elimination of radionuclide occur

$$
C(t)=C_{0} \sum_{i=1}^{n} \frac{B_{i}}{\lambda_{i}+\lambda_{p}}\left(1-\mathrm{e}^{-\left(\lambda_{i}+\lambda_{p}\right) t}\right)
$$

For the elimination phase where no radionuclides are assumed to enter the organism:

$$
C(t)=C\left(t_{0}\right) \sum_{i=1}^{n} A_{i} e^{-\left(\lambda_{i}+\lambda_{p}\right) t}
$$

where: $C(t)=$ radionuclide concentration in the organism at time $t_{;} C_{0}=$ constant seawater radionuclide concentration during the experiment; $C\left(t_{0}\right)=$ radionuclide concentration at the start of the elimination phase (i.e. at the end of the accumulation phase); $\lambda_{p}=$ physical decrease rate of the radionuclide, related to the half-life $T_{p}$ by the relation $\lambda_{p}=(\ln 2) / T_{p} ; B_{i}$ and $\lambda_{j}=$ combinations of rate constants between one compartment and the others. These combinations vary according to the number of compartments required to represent the organism, but are assumed specific and invariable for a given organism and a given radionuclide. They are sometimes called 'biological constants': - The constant $B_{1}$ represents the accumulation of 
radionuclides by the $i^{\text {th }}$ compartment of the organism,

- $\lambda_{i}$ characterizes the elimination of radionuclides by the $i^{\text {th }}$ compartment of organism. A practical concept, analogous to the half-life of a radionuclide, is associated with these parameters: the biological half-life or biological period. This is the time required for the compartment to eliminate by means of biological processes half of its initial concentration of radionuclides. The relation $\lambda_{j}=(\ln 2) / T b_{i}$ is used where $T b_{i}$ is the biological period of compartment $i$.

Parameter $A_{i}$ represents the contribution of the $i^{\text {th }} \mathrm{com}$ partment of the organism to the depuration process and therefore the relation $\operatorname{sum}\left(A_{i}\right)_{i=1 \ldots n}=1$ must be satisfied.

The formulation for the accumulation phase is valid provided the radionuclide concentration in seawater remains constant and the radionuclide concentration in the organism at the start of the experiment is negligible. The fluctuations in concentration that can be observed in situ in seawater cannot be formalised in this simple way and the complex dynamics of concen- trations in the environment must be included in the model.

For this purpose, the working hypothesis that was finally adopted successively:

- transforms the observed series of radionuclide concentrations in the seawater around the organism into a function which is constant per interval;

- uses the model described above to calculate the concentration accumulated by the organism for each interval of this function;

- corrects the calculated concentration to take into account the organism's history, i.e. previously accumulated concentrations.

The last point implies expanding the 'laboratory' model by removing the assumption of zero concentration in the organism at the start of each interval of the source function. The model must therefore be re-formulated.

A variable source term observed from $t_{0}$ to $t_{m}$ and described using $m$ different $C_{(j-1) j}$ values of radionuclide concentration (Fig. $2 b$ ) is used to calculate the concentration of radionuclides observed in the organism at time $t$ included in a time interval $\left[t_{k}, t_{1}\right]$.

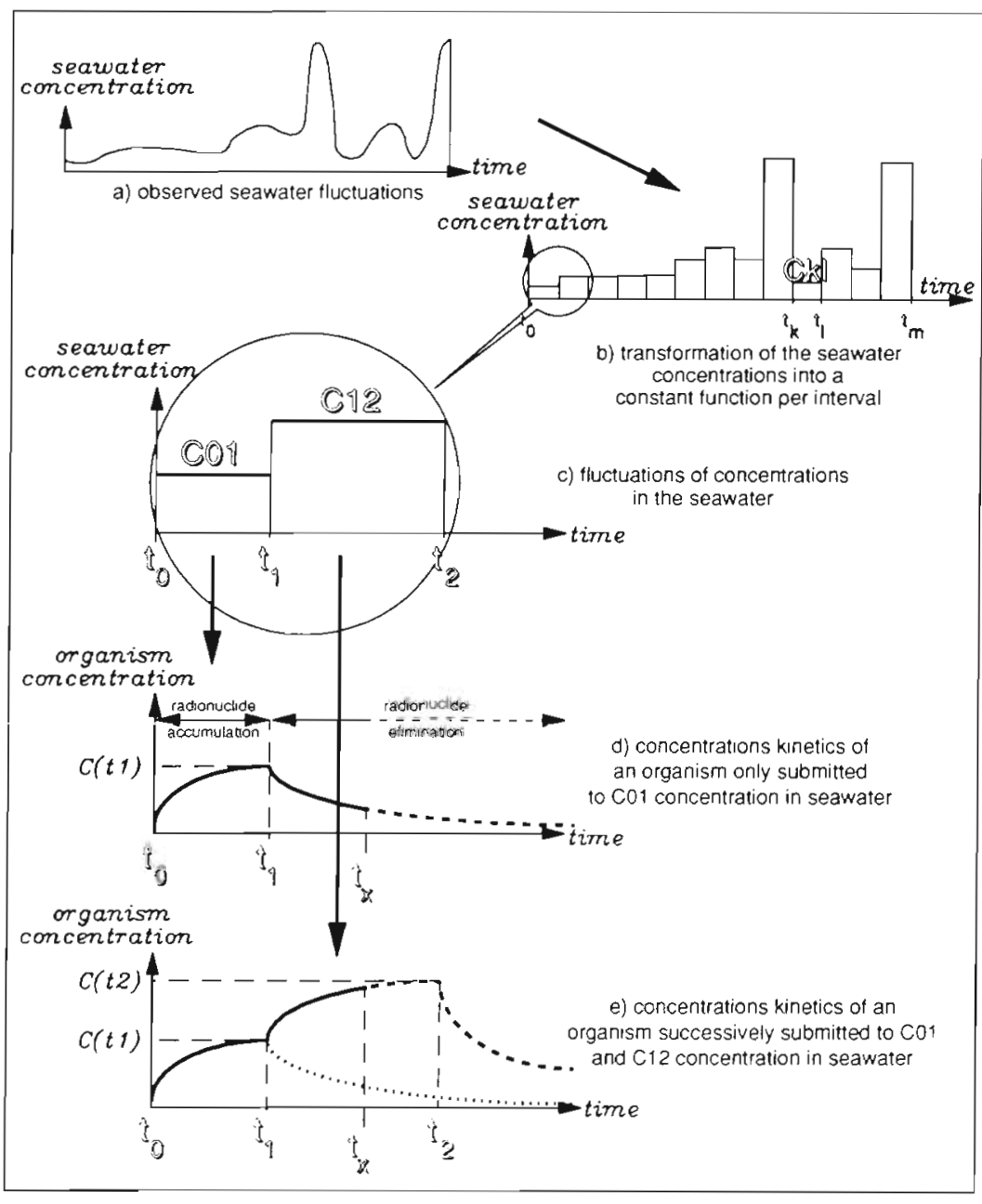

Fig. 2. Modelling the radionuclide concentration kinetics of an organsm submitted to a fluctuating seawater concentration of radionuclide 
Suppose that the organism is subject only to the environmental concentration $C_{01}$ (Fig. 2c).

At time $t_{1}$, the concentration of radionuclides in the organism is, according to the model described above (Fig. 2d):

$$
C\left(t_{1}\right)=C_{01} \sum_{i=1}^{n}\left[\frac{B_{1}}{\lambda_{i}+\lambda_{p}}\left(1-\mathrm{e}^{-\left(\lambda_{i}+\lambda_{p}\right)\left(t_{i}-t_{0}\right)}\right)\right]
$$

For a given time $t_{x}$, greater than $t_{1}$, the concentration in the organism, now in elimination phase, is (Fig. 2d):

$$
C\left(t_{x}\right)=C\left(t_{1}\right) \sum_{i=1}^{n}\left[A_{i} \mathrm{e}^{-\left(\lambda_{i}+\lambda_{p}\right)\left(t_{x}-t_{i}\right)}\right]
$$

The same organism is now subjected from $t_{1}$ to $t_{2}$ to a different level of concentration in water of $C_{12}$ (Fig. 2c). The concentration in the organism at a time $t_{x}$ between $t_{1}$ and $t_{2}$ is equal to the sum of the responses to 'stimulation' $C_{01}$ from $t_{0}$ to $t_{x}$ (Eqs. 3 and 4 ) and the responses to 'stimulation' $C_{12}$ from $t_{1}$ to $t_{x}$, i.e. (Fig. 2e):

$$
\begin{aligned}
C\left(t_{x}\right)= & \\
C_{01} \sum_{i=1}^{n}[ & {\left[\frac{B_{i}}{\left(\lambda_{2}+\lambda_{p}\right)}\left(1-\mathrm{e}^{-\left(\lambda_{1}+\lambda_{p}\right)\left(t_{1}-t_{0}\right)}\right)\right] \sum_{i=1}^{n}\left[A_{1} \mathrm{e}^{-\left(\lambda_{1}+\lambda_{p}\right)\left(t_{x}-t_{1}\right)}\right] } \\
& \quad+C_{12} \sum_{i=1}^{n}\left[\frac{B_{1}}{\left(\lambda_{i}+\lambda_{p}\right)}\left(1-\mathrm{e}^{-\left(\lambda_{1}+\lambda_{p}\right)\left(t_{x}-t_{1}\right)}\right)\right]
\end{aligned}
$$

Simplifying, the first term in Eq. (5), i.e.:

$C_{01} \sum_{i=1}^{n}\left[\frac{B_{i}}{\left(\lambda_{1}+\lambda_{p}\right)}\left(1-\mathrm{e}^{-\left(\lambda_{1}+\lambda_{p}\right)\left(t_{1}-t_{0}\right)}\right)\right] \sum_{i=1}^{n}\left[A_{i} \mathrm{e}^{-\left(\lambda_{1}+\lambda_{p}\right)\left(t_{x}-t_{1}\right)}\right]$ may also be expressed (Le Fur 1990):

$$
C_{01} \sum_{i=1}^{n}\left[\frac{B_{1}}{\left(\lambda_{j}+\lambda_{p}\right)}\left(\mathrm{e}^{-\left(\lambda_{1}+\lambda_{p}\right)\left(t_{x}-t_{1}\right)}-\mathrm{e}^{-\left(\lambda_{1}+\lambda_{p}\right)\left(t_{x}-t_{0}\right)}\right)\right]
$$

In general, using a variable source term, observed from $t_{0}$ to $t_{m}$ and described using $m$ different $C_{(j-1) j}$ values of radionuclide concentration (Fig. 2a), the concentration of radionuclides observed in the organism at time $t$ included in a time interval $\left[t_{k}, t_{1}\right]$ is expressed as:

$$
\begin{aligned}
C(t)=\sum_{j=1}^{k} & {\left[C_{(j-1) j} \sum_{i=1}^{n}\left[\frac{B_{1}}{\left(\lambda_{i}+\lambda_{p}\right)}\left(e^{-\left(\lambda_{i}+\lambda_{p}\right)\left(t-t_{j}-1\right)}\right)\right]\right] } \\
& +C_{k i} \sum_{i=1}^{n}\left[\frac{B_{i}}{\left(\lambda_{i}+\lambda_{p}\right)}\left(1-\mathrm{e}^{-\left(\lambda_{1}+\lambda_{p}\right)\left(t-t_{k}\right)}\right)\right]
\end{aligned}
$$

Where the organism radionuclide concentration at the very start of the experiment is not equal to zero, the following corrective term is added:

$$
C\left(t_{0}\right) \sum_{i=1}^{n} A_{i} \mathrm{e}^{-\left(\lambda_{i}+\lambda_{p}\right) t_{x}}
$$

which represents depuration of the initial radionuclide concentration in the organism.

Two series of data are required to use the model: (1) values of the radionuclide concentrations in water over time, expressed as a constant function for each interval;
(2) the biological parameters $B_{i}$ and $\lambda_{i}$ ( $i=1$ to $n$ compartments) specific to the organism.

(1) Formalization of the source term: in order to arrive at a function expressing the variation of concentrations in the water fully defined for the entire period under study (constant function per interval), each observed value of the water concentration is extended over a set time-interval. This simple method may cause localized over-or under-estimates of the activity levels actually present in the seawater. In order to reduce this bias, the maximum number of possible values over a given time interval was used.

(2) Parameters $\lambda_{i}$ (and $A_{i}$ ) are estimated using concentration measurements obtained during the elimination phase and the model associated with this phase (Eq. 2).

Then, by compiling values measured during both accumulation and elimination phases, a series of radionuclide concentrations in the organism is constructed. Together with the parameters $\lambda_{i}$ and the source function, it will be used to give estimates of missing parameters $B_{i}$ and therefore to define completely the model described in Eq. (6).

The criterion used for determining the best values of estimated parameters is the minimisation of the Error Sum (ES) which is the sum of square residuals between the observed values and the values calculated by the model. The optimization method used, which is well adapted to the minimisation of the ES, is that described as the Gauss-Marquardt method. This is an iterative, convergent method adapted to the non-linear estimation of parameters. This method was used for this work using an algorithm described by Jolivet (1982) as HAUSS-59.

\section{RESULTS AND DISCUSSION}

The biological elimination parameters $\left(\lambda_{i}\right)$ were first determined using results obtained during the second experiment (elimination at Roscoff). These parameters were then used to determine the $B_{1}$ parameters during analysis of the accumulation phase.

\section{Elimination phase}

The best adjustment of the model describing the kinetics of the elimination of ${ }^{106} \mathrm{Ru}$ by Mytilus edulis was achieved by representing the organism as 2 compartments (Fig. 3). This adjustment explains more than $90 \%$ of the total variance (Table 1 ). The biological periods estimated are of the order of $12 \mathrm{~h}$ for the rapid compartment and $200 \mathrm{~d}$ for the slow compartment. The slow compartment accounts for over $70 \%$ (parameter $A_{2}$ ) of the total ${ }^{106} \mathrm{Ru}$ concentration in the organism. 


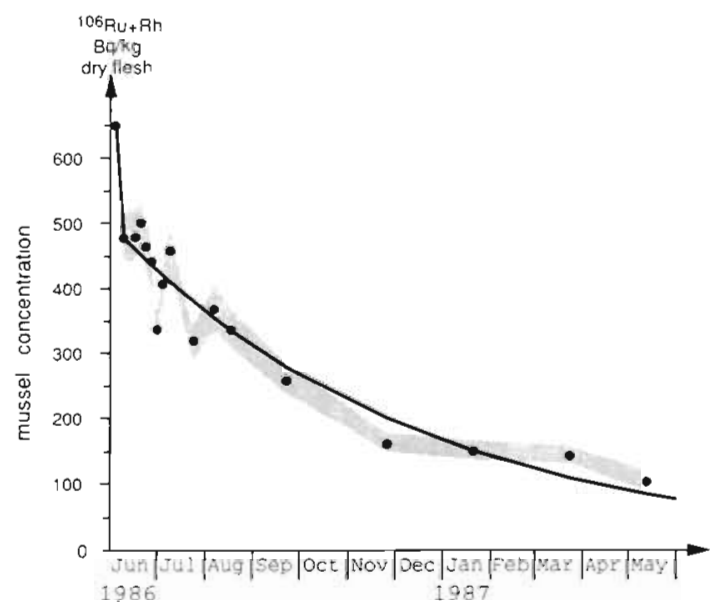

Fig. 3. Mytilus edulis. ${ }^{106} \mathrm{Ru}$ depuration at Roscoff: dry flesh observed concentrations (dots), associated gamma counting error range (shaded area) and model adjustment (thick line). The 2 half-lives are 0.5 and $213 \mathrm{~d}$

It is difficult to make comparisons between the results presented here and those obtained from laboratory experiments because of the difference in conditions in the 2 environments (Patel 1975). Very few experiments have been carried out on the in situ elimination of ruthenium by mussels. Two have been selected for consideration:

Clifton et al. (1983) describe an experiment on the accumulation and elimination by Mytilus edulis of several radionuclides (including ${ }^{106} \mathrm{Ru}$ ) discharged by the fuel reprocessing plant at Sellafield (U.K.). This experiment was carried out between 1980 and 1981. Using results from the elimination phase, taken over a long period of time, these workers obtained in situ elimination periods for ruthenium of the same order of magnitude as those found here: $6 \mathrm{~h}$ for the fastest component and $260 \mathrm{~d}$ for the slowest. Their analysis includes an intermediate compartment characterized by a biological period of $12 \mathrm{~d}$.

Masson et al. (1983) carried out an experiment on the transfer of ${ }^{106} \mathrm{Ru}$ between Mytilus edulis and its environment. This experiment was carried in 1980, in northwest Cotentin for a 3 mo accumulation phase and in southeast Cotentin for an elimination phase of the same length. The ruthenium originated from the reprocessing plant at La Hague. The biological period calculated by the authors was $18 \mathrm{~d}$, obtained by graphical analysis. Using the methods for estimating parameters described above, the model (Eq. 2) was applied to the results of the experiments of Masson et al. A similar biological period (ca $10 \mathrm{~d}$ ) was found, representing more than $70 \%$ of the total concentration of ${ }^{106} \mathrm{Ru}$ in the mussels. Moreover, a second, slower, component was revealed, characterized by a biological period of the order of $200 \mathrm{~d}$.

The above studies thus revealed a third elimination component not demonstrated in the present experiment, characterized by a biological period of ca $10 \mathrm{~d}$. It therefore appeared that one of the elimination mechanisms had been overlooked. The results of the present experiment were then re-worked and the model was re-adjusted, this time considering the concentration in the organism at the start of the elimination experiment after the 24 h clearance (faeces and pseudo-faeces). New biological periods of 14 and $264 \mathrm{~d}$ were obtained. Since the missing compartment (with the period of ca

Table 1. Mytilus edulis. ${ }^{106} \mathrm{Ru}$ depuration (dry flesh): results of fitting (see Eq. 2) and literature comparisons. \% Explained: percentage of the total variance explained by the model; this quantity (Jolivet 1982) is given by: $100 \times(1-$ sum of squared residuals/sum of squared observed values)

\begin{tabular}{|c|c|c|c|c|c|c|c|}
\hline \multirow[t]{3}{*}{ Source } & \multicolumn{6}{|c|}{ Results of fitting } & \multirow[t]{3}{*}{$\%$ Explained } \\
\hline & \multicolumn{2}{|c|}{ 1st compartment } & \multicolumn{2}{|c|}{ 2nd compartment } & \multicolumn{2}{|c|}{ 3rd compartment } & \\
\hline & $\begin{array}{l}A_{1} \\
(\%)\end{array}$ & $\begin{array}{l}T_{b 1} \\
(d)\end{array}$ & $\begin{array}{r}A_{2} \\
(\%)\end{array}$ & $\begin{array}{l}T_{\mathrm{b} 2} \\
\text { (d) }\end{array}$ & $\begin{array}{l}A_{3} \\
(\%)\end{array}$ & $\begin{array}{l}T_{\text {b3 }} \\
\text { (d) }\end{array}$ & \\
\hline Clifton et al. (1983) & 8 & 0.25 & 47 & 12 & 34 & 260 & \\
\hline Masson et al. (1983) & & & & 18 & & & \\
\hline $\begin{array}{l}\text { Masson et al. (1983) } \\
\text { (recalculated) }\end{array}$ & & & 74 & 10 & 26 & 209 & 98.3 \\
\hline $\begin{array}{l}\text { This work: } \\
2 \text { compartments } \\
c\left(t_{0}\right) \text { uncleared }\end{array}$ & 25 & 0.50 & & & 75 & 213 & 90.1 \\
\hline $\begin{array}{l}\text { This work: } \\
2 \text { compartments } \\
C\left(t_{0}\right) \text { cleared }\end{array}$ & & & 17 & 14 & 83 & 264 & 89.1 \\
\hline $\begin{array}{l}\text { This work: } \\
3 \text { compartments } \\
C\left(t_{0}\right) \text { uncleared }\end{array}$ & 11 & $\begin{array}{l}\text { Unable } \\
\text { to } \\
\text { compute }\end{array}$ & 13 & 19 & 76 & 254 & 89.8 \\
\hline
\end{tabular}


10 d) could also be identified from the data, the organism was then represented using 3 compartments and considering concentrations in the mussels measured without prior clearance. The adaptation value was not improved and the calculation did not succeed in revealing the rapid component (see Table 1). A sensitivity function analysis suggested that this was due to the small amount of data available at the start of the experiment (i.e. during the first $2 \mathrm{~d}$ ). Moreover, this first component only accounts for a small proportion of the total concentration of ruthenium in the organism (Clifton et al. 1983). Since the gamma counting error was of the same order as the contribution, the difficulty in revealing the first compartment during the calculations will be appreciated.

Compilation of the results (see Table 1) shows excellent corroboration between the different biological periods obtained. The congruity of the results obtained is particularly satisfactory considering that the 3 experiments (Clifton et al. 1983, Masson et al. 1983 and the present study) were carried out under different environmental conditions (dates, nature of the effluent and geographical position of the sites studied). The different contributions of each compartment that were obtained from one experiment to the other may be representative of these different environmental conditions.

This agreement would seem to demonstrate the specificity of the biological parameters $\lambda_{i}$ taken into account in the model. It is in agreement with the hypothesis that the parameters describing the elimination of ruthenium by mussels are independent of the type of discharge source and of the geographical loca-

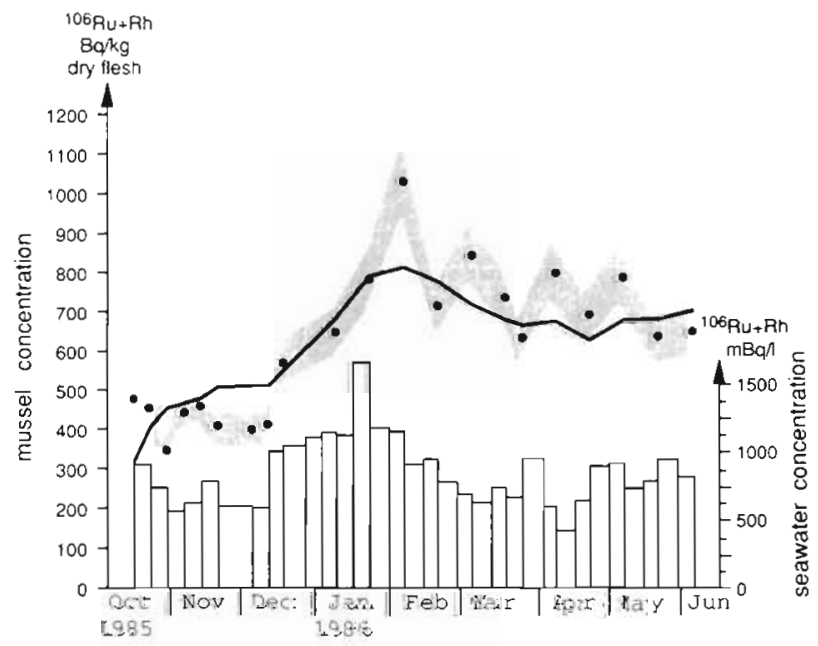

Fig. 4. Mytilus edulis. ${ }^{106} \mathrm{Ru}$ accumulation at Cherbourg; fitting of the model: dry flesh observed concentrations (dots), associated gamma counting error range (shaded area) and calculated kinetics (thick line). Bars represent seawater concentrations (constant function per interval) tion of the organism but are rather specific to the organism.

\section{Accumulation phase}

From all of the work referred to, 3 separate rate constants can therefore be extracted to represent the in situ elimination processes of ${ }^{106} \mathrm{Ru}$ by Mytilus edulis. These constants are periods of the order of a few hours, $10 \mathrm{~d}$ and more than $200 \mathrm{~d}$.

Since fitting the model for 3 compartments proved impossible with the present experimental data a selection must be made from the pairs of biological periods established by adjusting the 2-compartment models, i.e. $14 / 264 \mathrm{~d}$ and $12 \mathrm{~h} / 213 \mathrm{~d}$ (see Table 1). During the accumulation phase, $24 \mathrm{~h}$ clearance (faeces and pseudo-faeces) was allowed. Therefore, the selected elimination parameters were those obtained with considering that clearance (i.e. biological periods of 14 and 264 d)

The series of concentrations of ruthenium in the mussels was obtained by juxtaposing the 21 measurements of the accumulation phase and the 17 measurements of the elimination phase. The source function, constant per interval ( $1 \mathrm{wk}$ ), was arrived at using the results of measurements on 32 samples of water taken. during the accumulation phase (see Fig. 4). In addition, a ' 0 concentration' was simulated in the water during the time interval corresponding to the elimination phase.

The results of the samples measured and the theoretical kinetics of the concentrations in the organism are shown for the accumulation phase in Fig. 4. From the total variance in concentrations, $82 \%$ is represented by the model under study. From the calculated curve, the response of the model to fluctuations of concentrations in the water gives a satisfactory representation of the overall tendency of variations observed in the organism. It can be therefore concluded that the experimental biological transfer model is valid and that it can be extended to utilization in situ

We would obviously not claim that the model represents all the complex interactions of an organism with its environment. It could in fact be considered that any factor influencing concentration variations in the organism might constitute an error factor if not taken into account in the model.

Examination of the concentrations observed in the organism shows, for example, a fairly clear break in the mean levels of ruthenium in the organism at midDecember. There seems to be a steady-state condition between the organism and its environment during the first $60 \mathrm{~d}$ of the experiment. An accumulation phase is then observed during the next $50 \mathrm{~d}$. This discontinuity is not taken into account by the model, which estab- 
lishes the kinetics from the start to the end of the accumulation experiment. The estimated parameters must take the 2 phases into account together during the adjustment. The possible presence of a steady-state at the start of the experiment therefore leads to an adjustment which moderates the intensity of the next accumulation phase.

Thus the coherence of the model with fluctuations in ruthenium concentrations observed in mussels has been demonstrated for both phases of the experiment (accumulation and depuration). In the accumulation phase, some fluctuations which were not taken into account lead us to believe that the model is incomplete; this will be elaborated on in the next step.

\section{Application to a test case}

With the third experiment, the model was applied, using the same parameters as before, to show the extent to which it and its associated parameters can be transposed to a different environmental situation. It produced the theoretical kinetics shown in Fig. 5 (thick line). Although the changes in concentration in the mussels were throughout, the levels estimated by the model were, on average, 1.4 times greater than those observed.

The mean concentrations in the water between the first experiment (mussels established on site in October 1985) and the third (established March 1985) were similar $\left(841 \pm 241\right.$ and $749 \pm 214 \mathrm{mBq} \mathrm{l}^{-1}$ respectively). However, the mean concentrations in the mussels were significantly different $(270 \pm 92$ and $659 \pm 163 \mathrm{~Bq} \mathrm{~kg}^{-1}$ respectively\}. The 2 batches of mus-

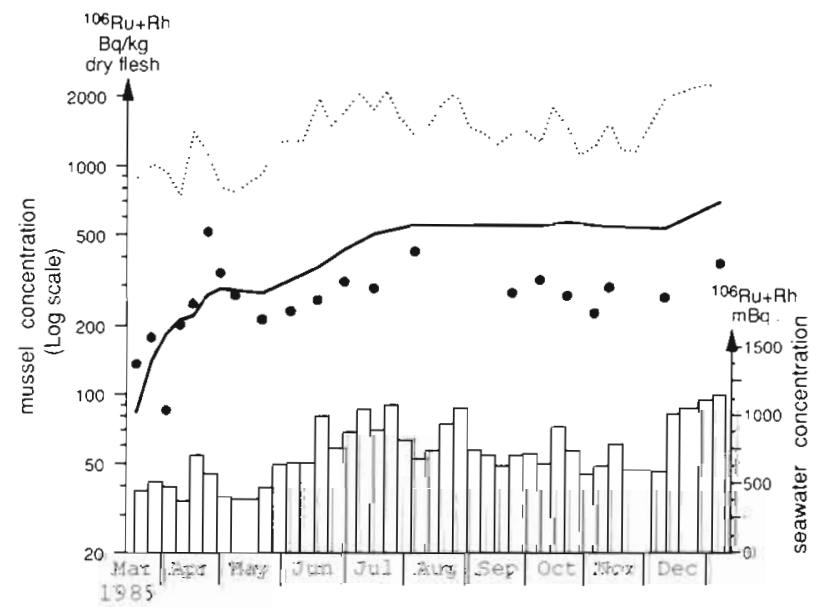

Fig. 5. Mytilus edulis. ${ }^{106} \mathrm{Ru}$ accumulation at Cherbourg; application to a test case: dry flesh observed concentrations (dots). associated gamma counting error range (shaded area), model calculated kinetics (thick line). Bars represent seawater concentrations (constant function per interval). Broken line gives estimates obtained by the $C F$ method $(C F=2000)$ sels thus reacted differently to the same stimulus (similar levels of concentration in the water). The model therefore did not take into account the factor(s) that contributed to the different levels observed from one experiment to the other. These may lie in 2 areas: the source of radionuclides, and the responses of the organism to variations in this source. As far as the source is concerned, the influencing factors may be as follows:

The physico-chemical condition of the radionuclide: quantities of ruthenium accumulated by an organism like the mussel can vary by a factor between 4 (Keckes et al. 1966) and 5 (Fraizier 1974) depending on the physical and chemical states of the ruthenium accumulated (laboratory experiments). Variations over time of the physical and chemical state of the ruthenium in Cotentin are not well known but it is possible that the chemical form of the element could have changed in the effluent between the 2 sampling periods (Guegueniat et al. 1988). Although it could be considered that the buffering effect of seawater would have minimized such differences, these variations in physical and chemical forms could have modified the availability of the ruthenium to the organism or the yield of the extraction technique for ruthenium in seawater.

The plurality of transfer routes: the model only takes transfer by water into account. It is clear that in the natural environment, an organism comes into contact with radionuclides present in all the compartments that make up its biotope (food, suspended matter, sediment, water). It was therefore attempted to establish whether one of the compartments not included in the model could have made a significant contribution to the accumulation of ruthenium by the mussels.

During the experiment, the mussels were suspended in cages and thus were not in contact with the sediment; the possibility of the sediment being responsible for a significant accumulation of ruthenium was therefore ruled out. Apart from transfer by water, which had been included in the model, radionuclides may be transferred by means of living or inert suspended matter, since the mussel is a filtering organism. The mean concentrations in suspended matter were found to be lower during the first experiment than during the test case $\left(191 \pm 195\right.$ and $243 \pm 157 \mathrm{~Bq} \mathrm{~kg}^{-1}$ respectively). The ${ }^{106} \mathrm{Ru}$ levels in suspended matter cannot therefore explain the higher concentrations observed in mussels during the first experiment

The mathematical representation of the source: the constant interval function, which represents variations in the seawater radionuclide concentrations, was established giving equal weight to all the measurements available. Thus the series of measurements carried out in the natural environment was the only source of information used in formulating the function. No 
hypothesis was devised concerning the response time of the organism. The water sampling carried out thus could be unrepresentative of the concentration variations in seawater which in fact influence those of the organism.

Although it is possible that components of the source which were not taken into account in the model were responsible for the poor evaluation, the second possible source of error lies in the fact that the model reduces the organism's metabolism to one of its simplest possible expression. It therefore needs to look at factors in the environment or the metabolism which affect the accumulation of radionuclides by the organism such as:

Acclimatization phase: a mussel population requires a period of several months (2 to 6 according to the physiological process under study) to acclimatize to a new site (Roesijadi et al. 1984, Widdows et al. 1984). The experiments carried out in the present work, and experiments in general concerning in situ estimation of biological parameters, necessitated transplanting mussels from one site to another. Thus, a fairly long acclimatization phase might have been a factor influencing the results obtained. In particular, the existence of an acclimatization phase in organisms on a new site could constitute one of the factors causing the low radionuclide accumulation observed in the mussels during the first 2 mo of the first experiment.

However, the comparative development of concentrations in the organisms led us rather to believe that the global differences observed between the 2 accumulation experiments were due to a break, at the end of 1985, in the time-course of a factor independent of either experimental mussel sample but rather connected with the time of year. The seasonal metabolic cycle of the organisms could thereby constitute this questionable factor.

The internal mechanisms of mussel metabolism are well known (Lubet 1963, Marteil 1976). The alternation of the different phases of the seasonal cycles has a great influence on the metabolic processes, especially those which are here of interest: in other words, the intake and output of matter between the organisms and their environment. This influence can be expressed in 2 ways.

(1) It can be expressed in modifications of the physiological functions. In this case, the intake/output parameters used in the model are not constant. Two attitudes then become possible: either taking a set of intake parameters into account which are specific to each phase of the cycle and which, taken individually, enable the continuity hypothesis to be considered valid (Badie et al. 1985); or considering variable parameters $B_{i}$, but this leads to non-linear systems which cannot be used to obtain an analytical solution (Atkins 1973).

(2) The various phases in the sexual cycle of mussels
(Lubet 1963) or variations in the quantities of food available in the environment (Colebrook 1985) cause seasonal variations in the weight of the organisms. Widdows (1978) has shown that the weight of the reproductive tissues of the mantle in a population of mussels in southwest England changed from 20 to $80 \%$ of total body weight between March and October. These weight variations are in inverse correlation with the time-course of the concentrations observed in the present work.

The experiment conducted by Clifton et al. (1983) leads to the same conclusion. They found that weight variations in the tissues of mussels modified by a factor of 2 the concentrations of radionuclides in the organisms between the end of the summer and the winter, independently of the source function. Weight variations of the organisms could therefore be the main factor to be taken into account in future experiments, since alterations over time of this factor are not yet taken into account in the model.

In this case where variations would be the main consequence of these seasonal metabolic variations, it may be enough to formulate the time-course of the weight of the organism and then to take this variation into account in the model, considering this factor as a control variable and keeping the transfer parameters constant.

\section{Comparison of forecasting techniques}

In a situation of chronic contamination, it could be assumed that the organisms under study are in radioactive equilibrium with their environment. This hypothesis is oversimplified and often invalid (results from the first experiment showed real kinetics of accumulation of ruthenium by Mytilus edulis). The hypothesis does, however, allow the use of methods based on the use of a concentration factor $(C F)$. The mussel concentrations were estimated using the $C F$ method, as an alternative to the model prediction.

To establish the best value for the CF to be applied to the experiment, results of earlier studies were compared (Table 2). The difference in values obtained during experiments carried out in situ and those in the laboratory immediately rule out $C F$ s associated with the latter. A confidence interval of several orders of magnitude was observed in CFs calculated using in situ observations. A CF of 2000 was selected, being an average of literature values, described in several references, and obtained in a similar contamination situation (see Vilquin et al. 1978).

The series of ruthenium concentrations calculated, using the $C F$ method and the measurements of radioactivity in seawater in the third experiment, are shown in 
Table 2. Mytilus edulis. Accumulation of water-borne ruthenium-106 concentration factors taken from the literature

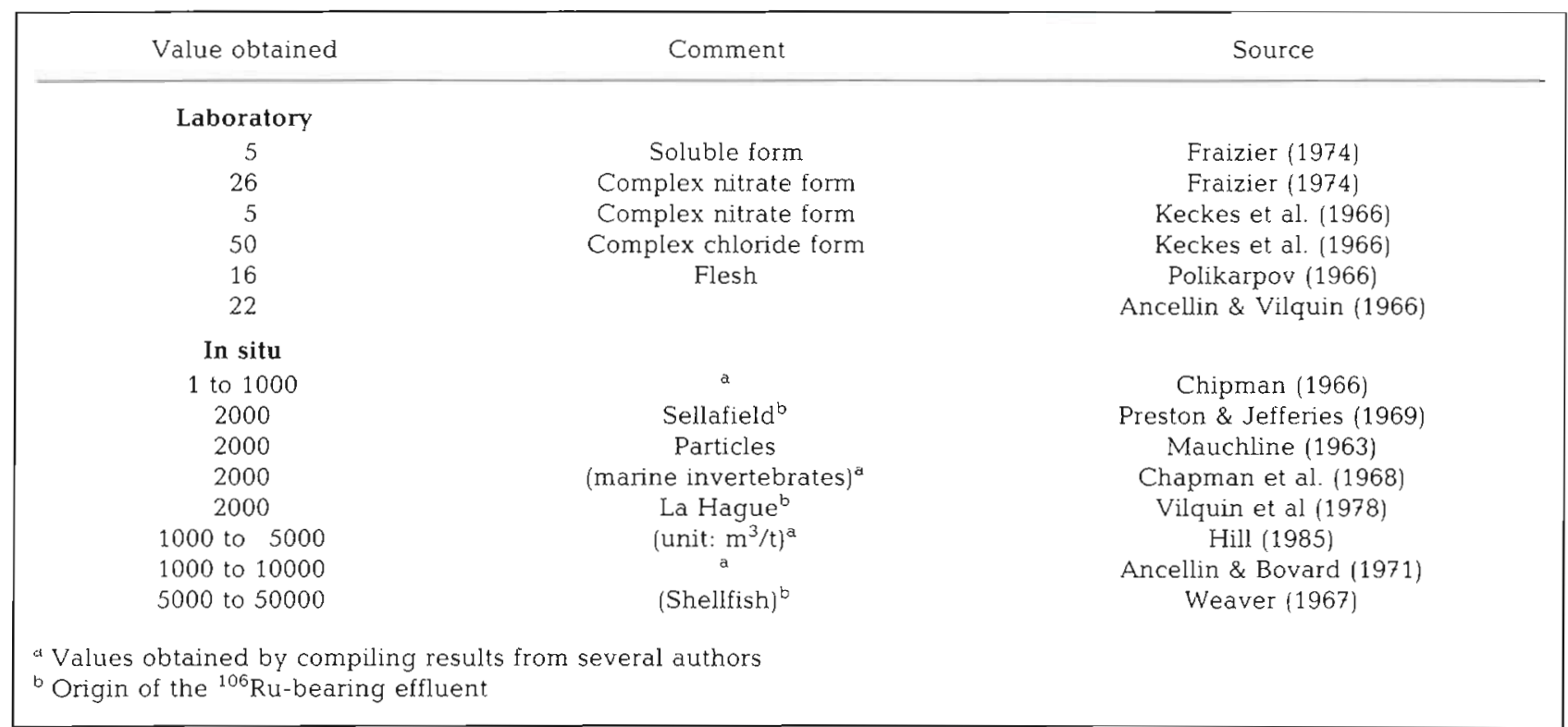

Fig. 5. The overall prediction gives concentrations 5 times greater than those actually observed. It will be noted that the time-course of concentrations calculated using the $C F$ method cannot be linked in any way to the variations observed. On the other hand, if the deviation in amplitude with the observed concentrations is ignored, the series of concentrations calculated using the model does express the overall tendency of the concentrations.

\section{CONCLUSIONS}

For the in situ transfer of ${ }^{106} \mathrm{Ru}$ between mussels Mytilus edulis and seawater, the biological phenomena under study can be represented by simple mechanisms (accumulation and elimination at constant rate formalized using ordinary differential equations). The mussels' ${ }^{106} \mathrm{Ru}$ concentrations depend, however, on a very large number of parameters and the main difficulty is in the correct evaluation of the processes to be modelled. This leads to the construction of empirically adjusted models in which uncertainty due to biological variability must be associated with the estimation of the parameters.

Previous studies led to the conclusion that the main factor to be represented in the model was the seasonal development of mussel metabolism, especially their weight. If this hypothesis is verified, it might be of interest to apply the model in order to specify times of year when the organisms accumulate radionuclide least actively. This would enable determination of the most favourable times for discharging radionuclides.
One of the interesting features of the model presented is its ability to account for fluctuations of environmental radionuclide concentrations in the corresponding concentrations estimated in the organisms A set of simulations should be undertaken to specify the nature of an organism's response to different types of source fluctuation, in particular where the problem of integrating fluctuations coming close together in time is concerned. This problem has already been mentioned in the literature (Iijima 1980) and studied by means of statistical procedures (Calmet 1986, Le Fur 1991).

When the model is considered in its simplest form (i.e. as described here) it can be expected, in a predictive application, to forecast at least the order of magnitude of the organisms' ${ }^{106} \mathrm{Ru}$ concentrations. This may be especially true when there is a good agreement between estimates obtained with mussels of different origins, as was the case here for the elimination parameters. This is not the case when using the CF method for which the inaccurate estimates obtained point out the difficulty of using this standard parameter from the literature, even when it was determined from similar contamination situations.

Furthermore, this latter method cannot be applied to the study of transfer to organisms in the case of an accidental contamination situation, for which a steadystate condition cannot be a valid hypothesis. It may then be assumed that the present model can take into account the fluctuations of organism radionuclide concentrations. Since the accumulation process would probably be fast (Preston \& Jefferies 1969), the contribution of the 'fast' compartment (parameter $A_{1}$ ) 
could increase significantly. Therefore the parameters $A_{1}$ should probably be re-evaluated.

Acknowledgement. The authors thank the staff of the marine station at Roscoff for their help during the sampling of the depuration phase.

\section{LITERATURE CITED}

Amiard-Triquet, C., Amiard, J. C. (1980). Radioécologie des milieux aquatiques. Masson, Paris

Ancellin, J., Bovard, P. (1971). Observations concernant les contaminations expérimentales et les contaminations 'in situ' d'espèces marines par le ruthénium 106. Rev. int. Océanogr. Méd. 21: 85-91

Ancellin, J,, Guegueniat, P., Germain, P. (1979). Radioécologie marine: étude du devenir des radionucléides rejetés en milieu marin et application à la radioprotection. Eyrolles, Paris

Ancellin, J., Vilquin, A. (1966). Contaminations expérimentales d'espèces marines par le cérium-144, le ruthénium106 et le zirconium-95. In: IAEA (ed.) Disposal of radioactive wastes into seas, oceans and surface waters. IAEA Proc. Ser., IAEA, Vienna, p. 583-604

Aoyama, I., Inoue, Y. (1973). Estimation and evaluation of radioactive contamination through a food web in an aquatic ecosystem (1). An application of the compartmental model to transfer of radioactive substances through a food chain. J. Radiat. Res. 14: 375-381

Atkins, G. L. (1973). Modèles à compartiments multiples pour les systèmes biologiques. Gauthier-Villard, Paris

Badie, C., Belluau, M., Fernandez, J. M., Gontier, G. (1985). Transferts aux organismes marins: analyse et synthèse des expérimentations menées au laboratoire de Radioécologie Marine de Toulon. Rep. CEA/EdF

Bernhard, M., Brushi, A., Moller, F. (1971). The use of simple models in radioecology. Mar. Radioecol., RTPROT(72) 12: 129-187

Calmet, D. (1986). Synthèse radioécologique des différents compartiments de l'environment marin du Cotentin. Thèse d'état Sciences, Univ. Aix-Marseille II

Chapman, W H., Fisher, H. L., Pratt, M. W. (1968). Concentration factors of chemical elements in edible aquatic organisms. Lawrence Livermore Lab., UCRL-50564, TID4500, UC-48, Biology and Medicine

Chipman, W. A. (1966). Food chains in the sea. In: Russel, S (ed.) Radioactivity and human diet, chap. 19. Pergamon Press, Oxford, p. 419-453

Clifton, R. J., Stevens, H. E., Hamilton, E. I. (1983). Concentration and depuration of some radionuclides present in a chronically exposed population of mussels (Mytilus edulis). Mar. Ecol. Prog. Ser. 11: 245-256

Colebrook, J. M. (1985). Continuous plankton record: overwintering and annual fluctuations in the abundance of zooplankton. Mar. Biol. 84: 261-265

Dahlgaard, H. (1981). Bioindicators to monitoring radioactive pollution of the marine environments. Rep. Risø-R-443 (Risø National Laboratory)

Fraizier, A. (1974). Relation entre la forme physico-chimique du ruthénium-106 et les phénomènes observés expérimentalement chez diverses espèces marines. In: IAEA (ed.) Comparative studies of food and environmental contamination. IAEA Proc. Ser., IAEA-SM-175/42, IAEA, Vienna, p. $135-148$

Germain, P., Baron, Y., Masson, M., Calmet, D. (1988). Répar- tition de deux traceurs radioactifs $\left({ }^{106} \mathrm{Ru}-\mathrm{Rh},{ }^{60} \mathrm{Co}\right)$ chez deux espèces indicatrices (Fucus serratus, L., Mytjlus edulis, L.) le long du littoral français de la Manche. In: Guray, J. C., Guegueniat, P., Pentreath, R. J. (eds.) Radionuclides: a tool for oceanography. Elsevier Applied Sciences, London and New York, p. 312-320

Germain, P., Masson, M., Baron, Y (1979). Etude de la répartition de radionucléides émetteurs gamma chez des indicateurs biologiques littoraux des côtes de la Manche et de la mer du Nord de février 1976 à février 1978. Rep. CEA-R5017. CEN-Saclay/doc, 91190 Gif/Yvette, France

Goldberg, E. D., Bowen, V T., Farrington, J. W., Harvey, G. Martin, J. H., Parker, P. L., Risenbrough, R. W., Robertson W., Schneider, E., Gamble, E. (1978). The mussel watch Environ. Conserv. 5(2): 101-125

Guegueniat, P. (1975). Comportement physico-chimique du ruthénium de fission dans le milieu marir. Rep. CEA-R4644, CEN-Saclay/doc, 91190 Gif/Yvette, France

Guegueniat, P., Gandon, R., Baron, Y., Salomon, J. C., Pentreath, R. J., Brylinski, J. M., Cabioch, L. (1988). Utilisation de radionucléides artificiels $\left({ }^{125} \mathrm{Sb},{ }^{137} \mathrm{Cs},{ }^{134} \mathrm{Cs}\right)$ pour l'observation (1983-1986) des déplacements des masses d'eau. In: Guary, J. C., Guegueniat, P., Pentreath, R. J. (eds.) Radionuclides: a tool for oceanography. Elsevier Applied Sciences, London and New York, p. 312-320

Halford, D. K., Markham, O. D., White, G. C. (1983). Biological elimination rates of radioisotopes by mallards contaminated at a liquid radioactive waste disposal area. Health Phys. 45(3): 745-756

Hill, M. D. (1985). Data base for use in radioecological assessment and sensitivity analysis. In: Dickson, R. R., Gurbutt, P. A., Kershaw, P. J. (eds.) Interim oceanographic description of the north-east Atlantic site for the disposal of lowlevel radioactive wastes, 2. OCDE/NEA, Paris, p. 161-191

IAEA (1985). Sediment Kds and concentration factors for radionuclides in the marine environment. IAEA Tech. Rep Ser. 247

IFREMER (1984). Inventaire des secteurs conchylicoles du littoral Français. Rapport IFREMER (Institut Français de Recherche pour l'Exploitation de la MER), Secrétariat d'Etat Chargé de da Mer, Direction des Pêches Maritimes et des Cultures Marines, Centre d'Etudes Techniques de L'Equipement de L'Ouest.

Lijima, $T$ (1980). Dependence of bioaccumulation of radioactive materials in marine organisms on their concentrations in sea water around the organisms: Discussion from the standpoint of dose assessment. Translation of a paper in Proceedings of the 8th NIRS seminar on bioaccumulation of marine organisms and factors on which it depends at National Institute of Radiological Science in Chiba, Japan

Jefferies, D. F., Hewett, C. J. (1971). The accumulation and excretion of radioactive caesium by the plaice (Pleuronectes platessa) and the thornack ray (Raja clavata). J. mar. biol. Ass. U.K. 51: 411-422

Jolivet, E. (1982). Introduction aux modèles mathématiques en biologie. INRA et Masson, Paris

Keckes, S., Pucar, Z., Marazovic, L. (1966). The influence of the physico-chemical state form of ${ }^{106} \mathrm{Ru}$ on its uptake by the mussel from sea-water. In: Aberg, B., Hungate, F. D. (eds.) Radioecological concentration processes, Proc. int Symp. held in Stockholm 25-29 April, 1966. Pergamon Press, Oxford and New York, p. 993-994

Le Fur, J. (1990). Modélisation numérique des transferts de radioéléments artificiels en mer de Manche (processus hydrodynamiques, biologiques et sédimentaires). Rep. CEA-R-5221, CEN-Saclay/doc, 91190 Gif/Yvette, France

Le Fur, J. (1991). Une méthode numérique d'étude des fluctu- 
ations spatio-temporelles de la radioactivité au sein de bioindicateurs marins. J. Rech. Océanogr. 15(3/4): 119-123

Lubet, P. E. (1963). Physiologie des moules. Bull. Soc. Sci Vét. Med. Comp. Lyon (France) 65(1): 31-62

Marteil L. (1976). La conchyliculture française: biologie de l'huitre et de la moule. Rev. Trav. Inst. Pêches marit. 40(2): $125-320$

Masson, M., Leon, R., Miramand, P., Germain, P. (1983). Réponses in situ d'un indicateur biologique Mytilus edulis aux fluctuations des rejets radioactifs d'une usine de retraitement des combustibles irradiés. Rep. CEA-R-5211, CEN-Saclay/doc, 91190 Gif/Yvette, France

Mauchline, J. (1963). The biological and geographical distribution in the Irish sea of radioactive effluent from Windscale works, 1959 to 1960. UKAEA Rep., AHSB(RP) R 27 , U.K. At. Energy Authority, Wigshaw lane, Culcheth, Warrington, $\mathrm{GB}$

Patel, B. (1975). Field and laboratory compatibility. In: IAEA (ed.) Design of radiotracer experiments in marine and biological systems. IAEA, Vienna, p. 211-239

Pentreath, R. J. (1973). The roles of food and water in the accumulation of radionuclides by marine teleosts and elasmobranch fish. In: IAEA (ed.) Radioactive contamination of the marine environment. IAEA Proc. Ser., IAEA-SM-158/ 26. IAEA, Vienna, p. 421-436

Pentreath, R. J., Jefferies, R. D. (1971). The uptake of radionuclides by I-group plaice (Pleuronectes platessa) off the Cumberland coast, Irish sea. J. mar. biol. Ass. U.K. 51: 963-976

Preston, A., Jefferies, D. F. (1969). Aquatic aspects in chronic and acute contaminations situations. In: IAEA (ed.)

This article was submitted to the editor
Environmental contamination by radioactive material IAEA Proc. Ser., IAEA-SM-117/44, IAEA, Vienna, p. 183-2 11

Polikarpov, G. G. (1966). Radioecology in aquatic organisms. The accumulation and biological effect of radioactive substances. North-Holland, Amsterdam

Roesidaji, G., Young, J. S., Drum, A. S., Gurtisen, J. M. (1984). Behaviour of trace metals in Mytilus edulis during a reciprocal transplant field experiment. Mar. Ecol. Prog. Ser. 18: $155-170$

Thomann, R. V. (1981). Equilibrium model of fate of microcontaminants in diverse aquatic food chains. Can. J. Fish. Aquat. Sci. 38: 280-296

Vilquin, A., Coulon, R., Le Grand, J. (1978). Méthode d'évaluation des conséquences des rejets radioactifs du centre de la Hague. In: CEC (ed.) Les effluents radioactifs des usines de retraitement du combustible irradié. CEC Seminar on Radioactive Effluents from Nuclear Fuel Reprocessing Plants, Karlsruhe. CEC, Luxembourg, V/ $2266 / 78$, p. 363-383

Weaver, C. L. (1967). A proposed radioactivity concentration guide for shellfish. Radiol. Health Data and Rep., Sep. 1967: 491-494

Widdows, J. (1978). Combined effects of body size, food concentration and season on the physiology of Mytilus edulis. J. mar. biol. Ass. U.K. 58: 109-124

Widdows, J., Donkin, P., Salkeld, P. N., Cleary, J. J., Lowe, D. M., Evans, S. V., Thompson, P. E. (1984). Relative importance of environmental factors in determining physiological differences between two populations of mussels (Mytilus edulis). Mar. Ecol. Prog. Ser. 17: 33-47

Manuscript first received: August 15, 1990

Revised version accepted: May 14, 1991 